\title{
On Exploration of Interrelationships amongst various Challenges towards Architectural Designs in Shaping Future Cities
}

\author{
Arnav Jain \\ Techture Structures Private \\ Limited \\ Indore, India
}

\author{
Viraj Voditel \\ Techture Structures Private \\ Limited \\ Nagpur, India
}

\author{
Remica Aggarwal \\ Recventures Education \\ Services Private Limited \\ Delhi, India
}

\begin{abstract}
The paper is exploratory in nature. It explores the various challenges faced for architectural designs while shaping for future cities. It also hints on the application of ISM methodology for further establishing the hierarchical interrelationships amongst them.
\end{abstract}

The research work is an initial attempt in the upcoming field of IoT and Future Cities. The paper can be extended to the arena of Industry 4.0.

\section{Keywords}

Future cities; architectural designs; ISM methodology

\section{INTRODUCTION}

Cities are very important for many reasons be it because of its architecture and urbanism but also for the economy and politics. In addition, the urban population which is expected to double over the next 40 years puts additional challenges which needs to be addressed comprehensively and viewed holistically in the new city model. It is estimated that by 2050 , the world's population is expected to exceeds 10 billion people making overcrowded cities one of the most pressing issues of the present. Data analysis, machine learning, transportation developments, social technologies developments will have a direct impact on the issue of overcrowding and on our built environment more largely.

Present research work therefore explores the various challenges related architectural designing for future cities. It thereafter, establishes the inter-relationships amongst them using ISM methodology. The paper is arranged as follows : Section 2 describes the main challenges. Section 3 the ISM methodology. Section 4 describes the case example. Conclusions and future directions are present in Section 5 .

\section{CHALLENGES RELATED TO ARCHITECTURAL DESIGNING FOR FUTURE CITIES [1-10]}

2.1. Climate Change [CC] : Climate change is one of the most pressing matters to look to when discussing future cities. Buildings and construction together account for $38 \%$ of energy-related $\mathrm{CO}_{2}$ emissions. Refurbishment over demolition is advantageous and should be looked upon as the recent trend in architectural designing because of its utility towards saving money and time and reduced carbon emissions impact . Rapid climate change [RCC] pose a serious challenge therefore towards architectural designing.

2.2. Energy efficiency in buildings [EEE] : is another way to reduce $\mathrm{CO}_{2}$ emissions. The entire industry is going through a transformation catalysed primarily by BIM, which integrates the entire lifecycle of the built environment, and more recently, the Internet of Things (IoT). In addition to human behaviour, temperature control, power monitoring, water consumption, and real-time performance are all recorded and processed, strengthening the response of buildings towards human interactions. Our global average temperature rise needs to be kept below $1.5 \mathrm{C}$, which means that $\mathrm{CO}_{2}$ emissions need to decline by $45 \%$ from its 2010 levels by 2030 . Poor energy efficiency [PEE] in buildings is therefore a challenge. 2.3. Disruptive Technologies : Disruptive technologies tries to resolves the issues related to parametric urban planning as well as towards the response to human-centred products such as artificial lighting products designed to change every few minutes as well as simulating real natural light conditions . The tool delivers a layout that optimizes walkability, social interaction, mixed-use integration, and many other factors. Poor disruptive technologies [PDT] would be a challenge therefore towards architectural designing.

2.4. Declined use of Recycled Construction Materials [DRCM]: Innovation in construction materials is a necessity now in keeping pace with expensive budgets . The smartest way to address this issue is systematically using our own waste by reusing, recycling, and upcycling with the help of plastic waste-based materials, $\mathrm{CO} 2$ absorbing materials (such as CLT), renewable materials, and biomechanics.

2.5. Weak Coordination between Big Data and Human Behavior [WC]: Future cities are smart cities, and they will operate as one big data-driven ecosystem. Some of the most important aspects of the city that are currently being analyzed and which future design could further improve with data include walkability, accessibility, mixed uses, fluctuating usage levels [avoiding dead spaces] and the integration of different cultures and communities. Weak big data and human interaction is a challenge therefore.

2.6. Co-working and Co-living [CW-CL]: As the human population doubles itself, it will become critical to optimize the quality of public spaces, allowing communities to share and interact in spaces that are designed for accessibility and diversity. The quality of comfort in workspaces and housing will be measured through sensors providing real-time data. For example, a building could detect that the oxygen levels are low, making people feel tired and stressed, and automatically activate the ventilation systems in response. It could also connect to calendar apps and suggest spaces that are not being used in real time, optimizing the use of space. Poor Co-working and Co-living [PCW-PCL] is a challenge therefore. 
2.7. Fast changing needs of the humanity [FCN] [1-10]: The main challenge of designing new spaces or even modernizing existing ones lies in the fast-changing needs of humanity and the even faster-evolving technologies that surround and support these needs. A combination of humanoriented design and experimental data-driven methodologies creates a holistic interdisciplinary perspective that identifies both the human needs and the available technologies. Fast changing needs is a positive challenge towards architectural designing both in the built and virtual realms.

2.8. Concept of public space [CPS] [1-10] : With higher population density, urban dwellers have a greater need for open, green spaces or recreational areas. Today, we mustn't think of a building as a singular, isolated element but rather as part of a complex of streets, infrastructure, public spaces, and other buildings that can work together, create a city, and drive change.

2.9. Miscellaneous Changing forces [MCF][1-10] : Miscellaneous changing forces such as urbanization as driver of growth. In developing countries in Latin America, it might be as simple as population growth resulting from a high birth rate. Another example is China, where government policy encourages urbanization as a driver of economic growth, contributing to the creation of large new cities.

2.10 Quality of life [QoL] : In all cities, it is possible to analyze service quality, as well as the density of the citydwelling population, the percentage of people who work in the city, and the modes of transportation they use. We often think that quality of life is higher in cities than in rural areas, but a close examination reveals that the difference between the people in the weakest and richest economic strata is increasing.

\section{INTERPRETIVE STRUCTURAL MODELLING METHODOLOGY}

Suggested by Warfield [11], ISM works with the following steps: It starts with identifying the relevant elements and pairwise establishing the contextual relationship amongst them. Thereafter, a structural self-interaction matrix (SSIM) may be developed between two variables i.e. $i$ and $j$ establishing a "Lead to" relationship between criteria. Four symbols viz. V, $\mathrm{A}, \mathrm{X} \& \mathrm{O}$ are used for establishing the relationships. After that, a level partition matrix can be obtained based on establishing the precedence relationships and arranging the elements in a topological order. A Mic-Mac analysis is performed categorizing the variables in to autonomous, dependent, driver and linkage category. Finally, a diagraph can be obtained.

\section{CASE EXAMPLE}

Ten positive (or negative) challenges discussed above viz. Rapid climate change [RCC]; Poor energy efficiency [PEE] in buildings; Poor disruptive technologies [PDT]; Declined use of Recycled Construction Materials [DRCM]; Weak coordination between big data and human behavior [WC]; Poor Co-working and Co-living [PCW-PCL] ; Fast changing needs of humanity [FCN]; Concept of public spaces [CPS]; Miscellaneous changing forces [MCF] ; Quality of life [QoL] are further studied for possible inter-relationships with the help of ISM methodology. These have been identified through literature survey over search engines such as google scholar, exploring published articles available in Research gate, academia.edu etc. can be studied further for possible interrelationships using ISM methodology.

\subsection{Construction of Structural self- interaction Matrix (SSIM)}

This matrix gives the pair-wise relationship between two variables i.e. $i$ and $j$ based on VAXO. SSIM has been presented below in Fig 1.

\subsection{Construction of Initial Reachability Matrix and final reachability matrix}

The SSIM has been converted in to a binary matrix called the initial reachability matrix shown in fig. 2 by substituting V, A, $\mathrm{X}, \mathrm{O}$ by 1 or 0 as per the case. After incorporating the transitivity, the final reachability matrix is shown below in the Fig 3.

Fig 1: SSIM matrix for pair wise relationship amongst barriers

\begin{tabular}{|l|l|l|l|l|l|l|l|l|l|l|l|}
\hline $\begin{array}{l}\text { S. } \\
\text { No. }\end{array}$ & Barriers & 1 & 2 & 3 & 4 & 5 & 6 & 7 & 8 & 9 & 10 \\
\hline & & RCC & PEE & PDT & DRCM & WC & $\begin{array}{l}\text { PCW- } \\
\text { PCL }\end{array}$ & FCN & CPS & MCF & QL \\
\hline 1 & RCC & & V & V & V & V & V & V & V & V & V \\
\hline 2 & PEE & & & A & A & A & A & A & A & A & A \\
\hline 3 & PDT & & & & X & X & X & X & X & X & X \\
\hline 4 & DRCM & & & & & X & X & X & X & X & X \\
\hline 5 & WC & & & & & & V & A & A & A & V \\
\hline 6 & $\begin{array}{l}\text { PCW- } \\
\text { PCL }\end{array}$ & & & & & & & A & A & A & X \\
\hline 7 & FCN & & & & & & & & V & V & V \\
\hline 8 & CPS & & & & & & & & & X & A \\
\hline 9 & MCF & & & & & & & & & & X \\
\hline 10 & QoL & & & & & & & & & & \\
\hline
\end{tabular}


Fig 2: Initial reachability matrix

\begin{tabular}{|l|l|l|l|l|l|l|l|l|l|l|l|}
\hline $\begin{array}{l}\text { S. } \\
\text { No. }\end{array}$ & Barriers & 1 & 2 & 3 & 4 & 5 & 6 & 7 & 8 & 9 & 10 \\
\hline & & RCC & PEE & PDT & DRCM & WC & $\begin{array}{l}\text { PCW- } \\
\text { PCL }\end{array}$ & FCN & CPS & MCF & QoL \\
\hline 1 & RCC & 1 & 1 & 1 & 1 & 1 & 1 & 1 & 1 & 1 & 1 \\
\hline 2 & PEE & 0 & 1 & 0 & 0 & 0 & 0 & 0 & 0 & 0 & 0 \\
\hline 3 & PDT & 0 & 1 & 1 & 1 & 1 & 1 & 1 & 1 & 1 & 1 \\
\hline 4 & DRCM & 0 & 1 & 1 & 1 & 1 & 1 & 1 & 1 & 1 & 1 \\
\hline 5 & WC & 0 & 1 & 1 & 1 & 1 & 1 & 0 & 0 & 0 & 1 \\
\hline 6 & PCW-PCL & 0 & 1 & 1 & 1 & 0 & 1 & 0 & 0 & 0 & 1 \\
\hline 7 & FCN & 0 & 1 & 1 & 1 & 1 & 1 & 1 & 1 & 1 & 1 \\
\hline 8 & CPS & 0 & 1 & 1 & 1 & 1 & 1 & 0 & 1 & 1 & 1 \\
\hline 9 & MCF & 0 & 1 & 1 & 1 & 1 & 1 & 0 & 1 & 1 & 1 \\
\hline 10 & QoL & 0 & 1 & 1 & 1 & 0 & 1 & 0 & 1 & 1 & 1 \\
\hline
\end{tabular}

Fig 3: Final reachability matrix

\begin{tabular}{|l|l|l|l|l|l|l|l|l|l|l|l|l|}
\hline $\begin{array}{l}\text { S. } \\
\text { No. }\end{array}$ & Barriers & 1 & 2 & 3 & 4 & 5 & 6 & 7 & 8 & 9 & 10 & D.P \\
\hline & & RCC & PEE & PDT & DRCM & WC & $\begin{array}{l}\text { PCW- } \\
\text { PCL }\end{array}$ & FCN & CPS & MCF & QoL & \\
\hline 1 & RCC & 1 & 1 & 1 & 1 & 1 & 1 & 1 & 1 & 1 & 1 & 10 \\
\hline 2 & PEE & 0 & 1 & 0 & 0 & 0 & 0 & 0 & 0 & 0 & 0 & 1 \\
\hline 3 & PDT & 0 & 1 & 1 & 1 & 1 & 1 & 1 & 1 & 1 & 1 & 9 \\
\hline 4 & DRCM & 0 & 1 & 1 & 1 & 1 & 1 & 1 & 1 & 1 & 1 & 9 \\
\hline 5 & WC & 0 & 1 & 1 & 1 & 1 & 1 & 1 & 1 & 1 & 1 & 9 \\
\hline 6 & PCW- & 0 & 1 & 1 & 1 & 1 & 1 & 1 & 1 & 1 & 1 & 9 \\
\hline 7 & FCL & & & & & & & & 1 & & & 1 \\
\hline 8 & CPS & 0 & 1 & 1 & 1 & 1 & 1 & 1 & 1 & 1 & 1 & 9 \\
\hline 9 & MCF & 0 & 1 & 1 & 1 & 1 & 1 & 1 & 1 & 1 & 1 & 9 \\
\hline 10 & QoL & 0 & 1 & 1 & 1 & 1 & 1 & 1 & 1 & 1 & 1 & 9 \\
\hline & De.P & 1 & 10 & 9 & 9 & 9 & 9 & 9 & 9 & 9 & 9 & \\
\hline
\end{tabular}

D.P : Driving power ; De.P : Dependence power

\subsection{Level Partition}

From the final reachability matrix, reachability and final antecedent set for each factor are found. The elements for which the reachability and intersection sets are same are the top-level element in the ISM hierarchy. After the identification of top- level element, it is separated out from the other elements and the process continues for next level of elements. Reachability set, antecedent set, intersection set along with different level for elements have been shown below in table 4.3.1.

Table 4.3.1: Iteration I

\begin{tabular}{|c|c|c|c|c|}
\hline S. No. & $\begin{array}{l}\text { Reachabilit } \\
\text { y set }\end{array}$ & $\begin{array}{l}\text { Antecedent } \\
\text { set }\end{array}$ & $\begin{array}{l}\text { Intersect } \\
\text { ion set }\end{array}$ & Level \\
\hline 1. & 2 & $\begin{array}{l}1,2,3,4,5,6,7,8 \\
, 9,10\end{array}$ & 2 & \multirow[t]{3}{*}{ I } \\
\hline 2. & $\begin{array}{l}2,3,4,5,6,7,8 \\
9,10\end{array}$ & $\begin{array}{l}1,3,4,5,6,7,8,9 \\
10\end{array}$ & $\begin{array}{l}3,4,5,6,7, \\
8,9,10\end{array}$ & \\
\hline 3. & $\begin{array}{l}1,2,3,4,5,6,7, \\
8,9,10\end{array}$ & 1 & 1 & \\
\hline
\end{tabular}

Table 4.3.2: Iteration II

\begin{tabular}{|l|l|l|l|c|}
\hline S. No. & $\begin{array}{l}\text { Reachabilit } \\
\text { y set }\end{array}$ & $\begin{array}{l}\text { Antecedent } \\
\text { set }\end{array}$ & $\begin{array}{l}\text { Intersect } \\
\text { ion set }\end{array}$ & Level \\
\hline 2. & $3,4,5,6,7,8,9$, & $1,3,4,5,6,7,8$, & $\begin{array}{l}\mathbf{3 , 4 , 5 , 6 , 7}, \\
\mathbf{8 , 9 , 1 0}\end{array}$ & II \\
& 10 & 9,10 & $\mathbf{1}$ & \\
\hline 3. & 1 & 1 & $\mathbf{1}$ \\
\hline
\end{tabular}

Table 4.3.3: Iteration III

\begin{tabular}{|l|l|l|l|r|}
\hline S. No. & $\begin{array}{l}\text { Reachabilit } \\
\text { y set }\end{array}$ & $\begin{array}{l}\text { Antecedent } \\
\text { set }\end{array}$ & $\begin{array}{l}\text { Intersec } \\
\text { tion set }\end{array}$ & Level \\
\hline 3. & 1 & 1 & 1 & III \\
\hline
\end{tabular}

\subsection{Driving power and dominance diagram}

As we can see that there is no autonomous criteria. Criteria QoL, MCF, CPS,FCN,PCW,WC,DRCM and PDT are linkage criteria whereas criteria RCC are driver criteria and criteria $\mathrm{PEE}$ is dependent criteria. 


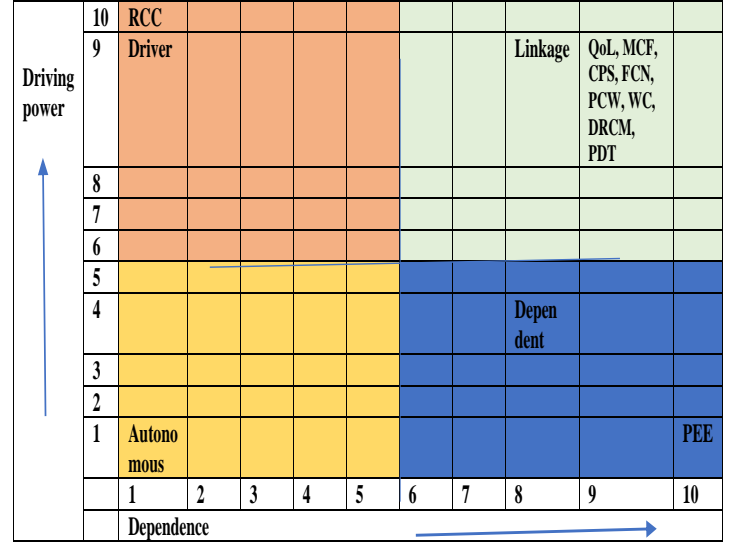

Figure 1: Driving power versus Dominance Diagram

\subsection{ISM --The Diagraph}

The diagraph presenting the hierarchy of the various barriers is shown in figure below:

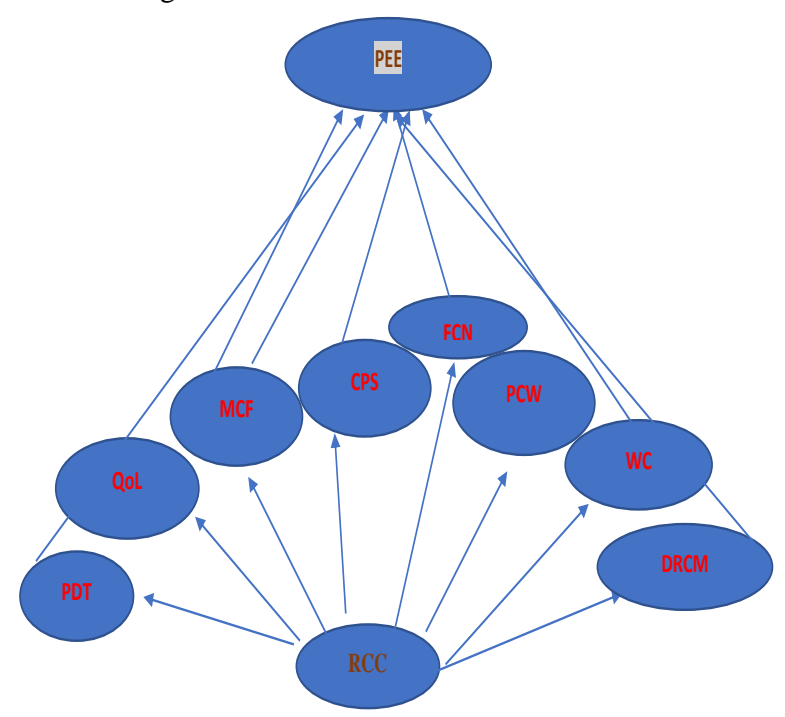

Figure 2: ISM Diagraph

\section{CONCLUSIONS}

Present research tries to establish the inter-relationships amongst the benefactors and challenges in architectural designing of smart cities with the help of ISM methodology.

\section{ACKNOWLEDGEMENTS}

Co-author Remica Aggarwal extend her sincere thanks to Prof. S.P. Singh, DMS, IIT Delhi for disseminating knowledge about ISM Methodology.

\section{REFERENCES}

[1] Booth Ksenia Chmutina , Lee Bosher , 2020. Scott protecting crowded places: Challenges and drivers to implementing protective security measures in the built environment . Cities, Vol. 107, Elsevier, https://www.ie.edu/insights/articles/cities-of-the-futurechallenges-of-architecture-and-design/

[2] https://www.ie.edu/insights/articles/cities-of-the-futurechallenges-of-architecture-and-design/

[3] https://www.archdaily.com/927262/7-architecturalconsiderations-that-are-shaping-future-cities

[4] https://www.africasurveyorsonline.com/2019/10/31/7architectural-considerations-that-are-shaping-futurecities/

[5] Designing for the future of the city - ResearchGate

[6] https://www.researchgate.net > publication > 283655954_.

[7] Cities of the Future: Challenges of Architecture and Design ...https://urbannext.net > cities-of-the-future

[8] https://architizer.com/blog/inspiration/collections/thefuture-of-architecture-cities/

[9] https://www.ie.edu/insights/articles/cities-of-the-futurechallenges-of-architecture-and-design/

[10] https://www.downtoearth.org.in/blog/urbanisation/futurecities-new-challenges-mean-we-need-to-reimagine-thelook-of-urban-landscapes-74671

[11] Warfield, J.N. 1974. Developing interconnection matrices in structural modelling, in the proceedings of IEEE Transactions on System, Man, and Cybernetics, SMC, 4 (1), 81-87. 